\title{
Endophilia or exophobia: beyond discrimination
}

Citation for published version (APA):

Feld, J. F., Salamanca Acosta, N., \& Hamermesh, D. (2013). Endophilia or exophobia: beyond discrimination. Maastricht University, Graduate School of Business and Economics. GSBE Research Memoranda No. 026 https://doi.org/10.26481/umagsb.2013026

Document status and date:

Published: 01/01/2013

DOI:

10.26481/umagsb.2013026

Document Version:

Publisher's PDF, also known as Version of record

\section{Please check the document version of this publication:}

- A submitted manuscript is the version of the article upon submission and before peer-review. There can be important differences between the submitted version and the official published version of record.

People interested in the research are advised to contact the author for the final version of the publication, or visit the DOI to the publisher's website.

- The final author version and the galley proof are versions of the publication after peer review.

- The final published version features the final layout of the paper including the volume, issue and page numbers.

Link to publication

\footnotetext{
General rights rights.

- You may freely distribute the URL identifying the publication in the public portal. please follow below link for the End User Agreement:

www.umlib.nl/taverne-license

Take down policy

If you believe that this document breaches copyright please contact us at:

repository@maastrichtuniversity.nl

providing details and we will investigate your claim.
}

Copyright and moral rights for the publications made accessible in the public portal are retained by the authors and/or other copyright owners and it is a condition of accessing publications that users recognise and abide by the legal requirements associated with these

- Users may download and print one copy of any publication from the public portal for the purpose of private study or research.

- You may not further distribute the material or use it for any profit-making activity or commercial gain

If the publication is distributed under the terms of Article $25 \mathrm{fa}$ of the Dutch Copyright Act, indicated by the "Taverne" license above, 


\section{Maastricht University}

Jan Feld, Nicolás Salamanca, Daniel S. Hamermesh

Endophilia or exophobia: beyond discrimination

$\mathrm{RM} / 13 / 026$

\section{GSBE}

Maastricht University School of Business and Economics

Graduate School of Business and Economics

P.O Box 616

NL- 6200 MD Maastricht

The Netherlands 


\title{
ENDOPHILIA OR EXOPHOBIA: BEYOND DISCRIMINATION
}

\author{
Jan Feld, Nicolás Salamanca and Daniel S. Hamermesh*
}

\begin{abstract}
The immense literature on discrimination treats outcomes as relative: One group suffers compared to another. But does a difference arise because agents discriminate against others-are exophobic —or because they favor their own kind - are endophilic? This difference matters, as the relative importance of the types of discrimination and their inter-relation affect market outcomes. Using a field experiment in which graders at one university were randomly assigned students' exams that did or did not contain the students' names, on average we find favoritism but no discrimination by nationality, and neither favoritism nor discrimination by gender, findings that are robust to a wide variety of potential concerns. We observe heterogeneity in both discrimination and favoritism by nationality and by gender in the distributions of graders' preferences. We show that a changing correlation between endophilia and exophobia can generate perverse predictions for observed market discrimination.
\end{abstract}

*Feld and Salamanca: Ph.D. candidates in economics, Maastricht University; Hamermesh: Sue Killam Professor of Economics, University of Texas at Austin, professor of economics, Royal Holloway University London, and research associate, IZA and NBER. We thank Jeannette Hommes, Ad van Iterson and Caroline Kortbeek for their assistance in making this experiment possible. Eric Bonsang, George Borjas, Hannah Ebin, Matthew Embrey, Ilyana Kuziemko, Arjan Non, Christopher Parsons, Joseph Price, Stephen Trejo, participants in seminars at a number of universities and institutes, and especially Leigh Linden provided very helpful comments. The Board of Examiners of the School of Business and Economics at Maastricht University formally approved this project. 
Although we could not perceive our own in-groups excepting as they contrast to outgroups, still the in-groups are psychologically primary. Hostility toward out-groups helps strengthen our sense of belonging, but it is not required. [Allport, 1954]

\section{Introduction}

Economists have studied labor-market discrimination at least since Becker (1957). Differences in labor-market and other outcomes by race, gender, ethnicity, religion, weight, height, appearance and other characteristics have been examined in immense detail, over time and in many economies. The focus has, however, been nearly exclusively on measuring differences in outcomes between groups, under the assumption that the "majority" group's outcome is the norm while the "minority" group is discriminated against. But since the only concept that is measured is a difference, it could just as easily be that the majority group is favored while the minority group's outcome is the norm.

The possibility that we are measuring the extent of favoritism rather than discrimination has been pointed out by Goldberg (1982) and by Cain (1986) in his survey; but beyond that the issue appears to have been completely neglected, including by the more recent Handbook surveys of the literature on discrimination (Altonji and Blank, 1999; Fryer, 2011). Once we recognize that favoritism need not be the obverse of discrimination, the importance of studying preferences for favoritism/discrimination increases. Although the distribution of discriminating agents' tastes underlay Becker's theory, in most empirical research the demand side — the behavior of discriminatory agents — has not been studied explicitly. Only recently has there been even a small upwelling of interest in examining their behavior and its impacts on outcomes, typically considering how agents' behavior toward those who match them along some dimension differs from their behavior toward those who do not match them. ${ }^{1}$ Even most of these studies, however, have looked only at averages, and none has combined the analysis of the distributions of preferences.

\footnotetext{
${ }^{1}$ See Price and Wolfers (2010) and Parsons et al. (2011) for evidence from professional sports; Dee (2005), Lavy (2008) and Hinnerich et al. (2011) for examinations of education; Cardoso and Winter-Ebmer (2010) and Giuliano et al. (2011) on wages and hiring; Baguës and Esteve-Volart (2010) on parliamentary elections; and Dillingham et al. (1994), Donald and Hamermesh (2006) and Abrevaya and Hamermesh (2012) for studies of economists' behavior.
} 
To distinguish clearly the who and the how in discrimination, we introduce four terms: Endophilia, endophobia, exophilia, and exophobia. The prefix endo refers to preferences towards people like oneself, the prefix exo to people unlike oneself. The suffix philia refers to favoritism and phobia to discrimination. Hence, endophilia denotes preferences for member of one's own group, while exophobia denotes preferences against members of other groups. One can also imagine, however, that some agents prefer members of other groups - are exophilic, while other agents are endophobic - discriminate against people like themselves.

Here we discuss the results of a field experiment that allows us to examine whether agents are endophilic and/or exophobic, and to characterize the distributions of the tastes of the discriminating/favoring agents. We do this by randomly revealing or concealing names on students' final exams, and thus randomly allowing or not allowing graders to infer the gender and nationality of the students. The key to separating endophilia from exophobia is that, instead of only having two groups with visible characteristics, we create two additional groups that have the same characteristics, except that they are anonymous and are arguably neither discriminated against nor favored by any of the agents. ${ }^{2}$ These groups provide two clear baselines against which we can measure endophilia/exophobia by the agents on the demand side. Hence, we identify endophilia (exophobia) as the treatment of members of one's own group (of another group) with visible names compared to the treatment of members of one's own group (of another group) with concealed names. We focus specifically on endophilia/exophobia by nationality and gender, but this method could be applied to any of the outcomes that have been studied in this immense literature.

\footnotetext{
${ }^{2}$ The only experiments like ours were conducted in laboratories (Fershtman et al., 2005; Ahmed, 2007). The latter had artificially-designated in- and out-groups; the former dealt with nationalities but was based on statements by students on how they would behave in a trust game. While laboratory evidence is useful, as discussed by Levitt and List (2007) it suffers from a number of difficulties that can be addressed in field experiments.
} 


\section{Empirical and Theoretical Motivation}

The importance of the distinction between favoritism and discrimination can be seen in a variety of ways. First, discrimination and favoritism can lead to different distributions of outcomes and to differences in overall welfare. Consider, for example, a supervisor who distributes a bonus payment of $\$ 300$ among one Black, one White and one Hispanic worker. The norm is to give $\$ 100$ to each worker, but a favoring (discriminating) supervisor will give $\$ 10$ more (less) to a certain worker. A supervisor who favors the White worker will give her $\$ 10$ extra, leaving $\$ 95$ each for the Black and Hispanic workers (B $=\$ 95, \mathrm{~W}=\$ 110, \mathrm{H}=\$ 95)$. A supervisor who discriminates against the Black worker gives her $\$ 10$ less, leaving $\$ 105$ each for the White and Hispanic workers $(\mathrm{B}=\$ 90, \mathrm{~W}=\$ 105, \mathrm{H}=\$ 105)$. In both cases the difference in outcomes between the White and the Black worker is $\$ 15$, but White-Hispanic relative wages differ under each alternative. The importance of this difference is strengthened if we consider convexity in utility and the likely differences in the initial situations of the workers. Under these conditions it is straightforward to show that, for the same gap in outcomes, the sum of utility losses is greater when the gap is generated by discrimination than when the gap is generated by favoritism.

Second, the concepts of endophilia and exophobia can be measured, albeit imperfectly, in the realworld, and these measures show that they are not necessarily opposite. Beginning in 1996, and biennially except in 2002, the U.S. General Social Survey has asked questions, "In general, how close do you feel to Whites [Blacks]?" with answers on a nine-point scale ranging from $9=$ very close to $1=$ not close at all. Table 1 describes these data, separating answers by Whites and Blacks, and pooling 1996-2000 as an early period, 2004-2006 as a later period. (We exclude the 2008 and 2010 data because the campaign and election of President Obama may have altered expressed preferences.) Several things stand out: 1) Unsurprisingly, expressed closeness to one's own group exceeds that to the other group; 2) While Whites' closeness to other Whites changed little over this period, there was a very large increase in their expressed closeness to Blacks; 3) There are only small changes in Blacks' expressed closeness to either Whites or Blacks; and 4) The correlation between expressed closeness to one's own and the other is positive and increases (significantly) between the two sub-periods. Implicitly, those who favor members of their own 
group more disfavor members of the other group less, or, in our terminology, there is a negative relation between endophilia and exophobia. Endophilia and exophobia are distinct concepts, not opposite sides of the same coin, and are notions that correspond mutatis mutandis to items included in social surveys.

The distinction between favoritism and discrimination has important theoretical implications. As Goldberg (1982) showed, if favoritism toward one's own group drives observed, apparently discriminatory differentials, these differentials can persist in a competitive market. Goldberg reached this conclusion by assuming favoritism preferences instead of the discriminatory preferences of Becker (1957). If, however, discrimination and favoritism are allowed to co-exist in this model, they will generate different predictions about measured intergroup wage differentials depending on the relationship between them. As an illustration, consider two polar cases: Case 1, the most endophilic employers are also the most exophobic - the correlation between tastes for members of one's own group and distastes for the other group is $\rho=+1$; and Case 2, the most endophilic employers are also the least exophobic - the correlation between tastes for members of one's own group and distastes for the other group is $\rho=-1$.

Assume, as Becker does in his model, that all employers are White, and assume too that the distribution of endophilia is $f(e)$ and of exophobia is $f(x)$. Also assume a fixed labor force, some fractions of which are White and Black. Further, assume for simplicity that White workers sort first into firms. ${ }^{3}$ In Case 1 the marginal White worker will be employed at the least endophilic among those employers who are sufficient in number to hire the White workers. Black workers will not seek jobs with these employers, since they are also the most exophobic. Instead, they will fill up jobs at the least exophobic employers (who happen also to be the least endophilic). ${ }^{4}$ The result, shown in Figure 1, is that the observed market discrimination coefficient, the ratio of white to black wages, is $\mathrm{MDC}_{1}=[1+\mathrm{e}] /\left[1-\mathrm{x}_{1}\right]$, where we have indexed the white wage in the absence of favoritism or discrimination to equal 1.

\footnotetext{
${ }^{3}$ This assumption simplifies our argument but is not needed, since the core of the argument relies on the competition for positions between Whites and Blacks.

${ }^{4}$ See Charles and Guryan (2008) for a discussion of the empirical importance of the marginal discriminator.
} 
In Case 2 both White and Black workers are seeking jobs with the same employers, the Whites because these employers are most endophilic, and the Blacks because they are least exophobic. Blacks are competing for the same jobs as Whites, and wind up taking jobs with those employers who are the least exophobic (and also the most endophilic) among the remaining employers. In this case the marginal Black employee is matched with a more exophobic employer, and thus Blacks face more measured discrimination: $\mathrm{MDC}_{2}=[1+\mathrm{e}] /\left[1-\mathrm{x}_{2}\right]>\mathrm{MDC}_{1}$. This example illustrates that differences in joint distribution of endophilia and exophobia generate different market wage differentials. For the same preferences, same distribution of employers, and same distribution of workers, the wage gap is smaller if the most bigoted (against blacks) employers are also those who favor Whites most.

\section{Constructing the Experiment}

\section{A. The Environment}

To make the distinction between favoritism and discrimination empirically we set up a field experiment that we carried out during the final exam week in June 2012 at the School of Business and Economics (SBE) of Maastricht University in The Netherlands. The language of instruction throughout the SBE is English. This environment has a number of features that make it particularly appropriate for distinguishing between favoritism and discrimination. Partly because Maastricht is near the German border, the SBE has a large share of German students (51 percent) and academic staff ( 22 percent) mixed with Dutch and other nationalities. The student population is 36 percent female, and the academic staff is 28 percent female. ${ }^{5}$ German students have a reputation for being more hard-working than Dutch and other students. These contrasts by nationality could potentially be the basis for discrimination/favoritism, although it is unclear a priori in which direction these will be. ${ }^{6}$

\footnotetext{
${ }^{5}$ The SBE homepage (http://www.fdewb.unimaas.nl/miso/index.htm) provides these statistics for enrolled students in 2010 for nationality and 2012 for gender. Statistics about staff refer to full-time-equivalent academic staff in 2012 and are taken from the internal information system "Be Involved."

${ }^{6}$ While it is often found that people favor (discriminate against) groups with same (different) characteristics, there are also situations in which the opposite is the case. One can, for example, think of many situations in which relative
} 
The grading of final exams, which we examine here, is a good setting for distinguishing the effects of tastes for discrimination from those of statistical discrimination, because graders do not gain anything from favoring or disfavoring specific groups. Also, until the teaching period that we examine all students were required to write their names on their exams, enabling the graders to identify the students' gender and nationality. ${ }^{7}$ Finally, and most important, this experiment has real-world consequences: The grades are important to students; also, much of the graders' jobs revolves around their role in scoring exams.

In the SBE written exams are given in ten sessions spread over a week, with many courses giving their exams simultaneously. Students in all the courses assigned to each session take their exams together in a large conference hall filled with desks that are arranged in blocks of 5 columns and 10 rows. ${ }^{8}$ To prevent cheating each student's desk is predetermined by the Exams Office (the organization responsible for examination procedures). The desk assignment is based on student ID numbers, first by sorting them from lowest to highest within each block, and then filling in sequentially within each column from left to right. ${ }^{9}$ Figure 2 illustrates the arrangement of desks in each block.

outcomes suggest that males are exophilic or endophobic (e.g., Donald and Hamermesh, 2006, although that study cannot distinguish between these two types of behavior).

${ }^{7}$ The grader can infer the nationality and gender of the students when she sees the family name, even if she does not know the student, because Dutch and German names are quite distinct. To test this we asked 9 staff ( 5 German and 4 Dutch, of whom 5 were female) to guess the nationality and gender of 50 student names from our sample. We selected the student names block-randomly to reflect the nationality mixture in our sample (19 German, 17 Dutch and 14 other nationalities, of whom 16 were female). The staff correctly identified the German names in 64 percent, the Dutch names in 65 percent and the gender in 90 percent of the cases.

${ }^{8}$ Exams in courses with more than 50 students are written in the same session in multiple blocks. Exams in courses with fewer than 50 students are either kept in one block or are combined with the exams in other courses. There are a few blocks that have as many as 12 rows.

${ }^{9}$ Student IDs are assigned in ascending order based on the moment a prospective student contacts Studielink (the Dutch centralized system for university application; https://app.studielink.nl/front-office/). This means that earlier cohorts have lower-number IDs, and later cohorts and exchange students have higher-number IDs. 


\section{B. The Experiment and Data Collection}

The students in each session arrive at the exam hall and locate their assigned block based on the course they are taking. Within the block they then locate their assigned desk, which is marked with their student ID number. Once the exam session starts students have three hours to complete their exams. During that time one invigilator (not the same person as the exam grader) supervises each block. We asked the invigilators to place yellow sheets on all desks in the first three rows of each block (see Figure 2), thus ensuring that the recipients were mixed by ID number, and thus more or less random by seniority in the University. The sheets stated that the students on whose desk one was placed should not write their name but only their ID number on the exam sheets. ${ }^{10}$ Because of the predetermined arrangement of desks this meant that a random sample of students within each course — the "blind" group—was asked not to write their names, so that the grader would only observe their ID numbers when grading. For the rest of the students - the "visible" group - graders could observe both names and IDs, as in previous teaching periods.

We collected additional information from several other sources. The Exams Office provided us with the nationality and gender of the students, grades in previous courses, and the desk arrangement during the exam. From the seating arrangement we could infer which students were asked not to write their names (yellow sheets, rows 1-3) and which were allowed to do so. To check students' compliance with the experiment's instructions, we manually went through all the exams and checked which students wrote down their names and which students did not. ${ }^{11}$

At the SBE it is common practice to split the grading burden among various graders by letting each one handle all the answers to a particular set of questions on the same exam. The course coordinators

\footnotetext{
${ }^{10}$ We blocked entire rows instead of scattered seats within each for simplicity. We treated rows instead of columns in order to capture students with a variety of high and low ID numbers within each course. The Exams Office informed the course coordinators - who were in charge of organizing the grading of the exams-before the examination period that a new examination procedure was being tested, so that some exams might only have ID numbers. They were asked to grade those exams as they usually would.

${ }^{11}$ This was done immediately after the exam, before the course coordinators received the exams to arrange the grading.
} 
identified the grader of each question and provided us with information on the grading. This information included the score on each question and the maximum possible points per question. They also provided us with other available grades that the student had attained in the course, including on course participation and any term paper. ${ }^{12}$ A survey sent after the grading to all graders and course coordinators provided information on the grader's gender, nationality, teaching experience and grading behavior during the experiment. ${ }^{13}$ From the SBE's online tool for course evaluations we gathered the total number of courses in which the grader had been involved at the SBE and the average instructor evaluations provided by the students for that grader in all previous courses since the creation of the online tool. Our sample contains 25 out of the 42 courses that had final exams, including 42 graders and 1,495 exams that were scored. ${ }^{14}$

The upper part of Table 2 examines the internal validity of the experiment, testing whether the questions in the treated (Visible) group were answered by students whose characteristics before they entered the examination room differed in measurable dimensions from those in the untreated (Blind) group. We present these results separately for those students whom we intended to treat (ITT) and those who were actually treated. ${ }^{15}$ We first examine differences by gender and nationality, the two characteristics on which we focus, and in the students' grades before the final exam. The Blind and Visible groups are balanced in both gender and nationality: The p-values indicate that none of the tests of differences in the means between the Blind and Visible groups along the dimensions that form the focus of this study can reject the hypothesis that they are zero. Indeed, not only are the fractions of men and

\footnotetext{
${ }^{12}$ Most course coordinators had this information readily available in an Excel file. We manually collected the scores on each exam question for 7 courses.

${ }^{13}$ We manually added the gender and nationality of the graders who did not fill out the survey. Grading behavior includes whether graders' looked up any names while grading.

${ }^{14}$ We excluded 8 courses that only used Multiple Choice or Fill-In-The-Blank questions. In 7 out of the 34 eligible courses the course coordinators either declined permission to use the data or did not respond to repeated requests for this information. We excluded one course for which we could not directly link the questions graded to unique graders. We also excluded another course which did not have the exam in the conference hall.

${ }^{15}$ The blind treatment group had a little over 80-percent effectiveness, and an additional 2 percent of the students got into the blind group but should not have. This latter was most likely due to mistakes by the invigilators when placing the yellow sheets or by students forgetting to write their names.
} 
women, Germans and Dutch, insignificantly different from each other; the absolute differences are never greater than two in the second decimal place between the Blind and Visible groups.

We have additional information on some of the students — other grades that were awarded before the exams were given, such as prior grade point average (GPA), and classroom participation, presentation in class and term-paper grades in the particular course. We find no significant differences between the Blind and Visible students in GPA and their participation grades. The Visible group performs slightly better in the grades assigned for student presentations. This difference is not quite statistically significant, however; and perhaps more important, grades for classroom presentations were given to only about onethird of the students.

We also have grades from the Multiple Choice and Fill-In-The-Blank questions that were included in a minority of the final exams. We can thus test whether, despite the apparent randomness of assignment, outcomes differed between the two groups on questions on which the grading was unambiguous and could not have been affected by the mechanisms we study here. As the bottom part of Table 2 shows, the Blind group did have marginally higher scores on the Multiple Choice questions, but here too the differences are not quite statistically significant. These results confirm that the research design created equivalent groups of students. ${ }^{16}$

\section{Inferring Average Outcomes and Distributions of Preferences}

Let a student, denoted by $s$, answer an exam with several questions, and let the grader of each question be denoted by $g$. We index each answer by the pair $(s, g) .{ }^{17}$ We also know the pair $(\mathrm{C}(s), \mathrm{C}(g))$, where $\mathrm{C}$ is either some student-invariant bivariate characteristic, such as gender, or some characteristic vector, such as nationality. Finally, we know whether a particular answer by a particular student was

\footnotetext{
${ }^{16}$ Considering that we tested several separate characteristics, it is not unlikely that some of those tests will reject the null hypothesis at the 10 percent level purely by chance. If we correct the p-values for multiple testing (using the Bonferroni, Šidák, or Holm adjustments), we find no significant differences between Blind and Visible students in any of the characteristics, even at the 10 percent level of significance.

${ }^{17}$ We ignore course identifiers for simplicity, since all graders except one were uniquely assigned to one course.
} 
graded blind or visible, so that each pair $(\mathrm{C}(s), \mathrm{C}(g))$ can be expanded to the triplet $(\mathrm{C}(s), \mathrm{C}(g), v)$, where $v=1$ if the grading is visible and 0 if not. ${ }^{18}$

Consider the score function $S(\mathrm{C}(s), \mathrm{C}(g), v)$ for each exam question, where we are especially interested in examining how $S$ varies between cases when $s$ and $g$ match (i.e. share a common characteristic) and when they do not, and how that variation is affected by $v$. Define the following indicators:

$$
\mathrm{I} 1\{(\mathrm{C}(s), \mathrm{C}(g), v)\}=1 \text {, if } \mathrm{C}(s)=\mathrm{C}(g) \text { and } v=1,0 \text { if not; }
$$

$$
\mathrm{I} 2\{(\mathrm{C}(s), \mathrm{C}(g), v)\}=1 \text {, if } \mathrm{C}(s)=\mathrm{C}(g) \text { and } v=0,0 \text { if not; }
$$$$
\mathrm{I} 3\{(\mathrm{C}(s), \mathrm{C}(g), v)\}=1 \text {, if } \mathrm{C}(s) \neq \mathrm{C}(g) \text { and } v=1,0 \text { if not; }
$$

and

$$
\mathrm{I} 4\{(\mathrm{C}(s), \mathrm{C}(g), v)\}=1 \text {, if } \mathrm{C}(s) \neq \mathrm{C}(g) \text { and } v=0,0 \text { if not. }
$$

The average score of all students is:

$$
\mathrm{T}=\theta_{1} S^{*}(\mathrm{I} 1)+\theta_{2} S^{*}(\mathrm{I} 2)+\theta_{3} S^{*}(\mathrm{I} 3)+\left[1-\theta_{1}-\theta_{2}-\theta_{3}\right] S^{*}(\mathrm{I} 4),
$$

where the weights $\theta_{i}$ are the shares of answers graded under each regime, and the $\left(^{*}\right)$ denotes an average over those answers. ${ }^{19}$ Because we created the neutral categories with blind grading, we can estimate the average treatment effect on students for whom $\mathrm{C}(s)=\mathrm{C}(\mathrm{g})$ (i.e., grader and student "match" on characteristic C) as:

$$
M_{M}=\left[S^{*}(\mathrm{I} 1)-S^{*}(\mathrm{I} 2)\right]
$$

and the treatment of students for whom $\mathrm{C}(i) \neq \mathrm{C}(\mathrm{g})$ (who do not "match" on $\mathrm{C}$ ) as:

$$
M_{N}=\left[S^{*}(\mathrm{I} 4)-S^{*}(\mathrm{I} 3)\right] .
$$

If graders are endophilic and exophobic, $M_{M}, M_{N}>0$. In Section V we present estimates of each of the effects discussed here.

\footnotetext{
${ }^{18}$ Presumably all particular $(s, g)$ combinations are either blind or visible (although we investigate the extent of blindness in the blind grading).

${ }^{19}$ While the same average would apply for a n-fold characteristic if we focus only on whether or not $\mathrm{C}(s)=\mathrm{C}(g)$, we could analogously and generally calculate $n^{2}$ average treatment effects, one for each of the $n$ aspects of the characteristic compared to itself and each other aspect.
} 
From Equation (2) we can also recover the average "total" effect of the characteristic $\mathrm{C}(s)$ for a particular value, $\mathrm{C}(s)=\mathrm{C}^{\prime}$. This is particularly important if we want to address the question of whether disclosing certain information (such as gender or nationality) affects an outcome, given a distribution of preferences and graders. Consider a variant of (2):

$$
T_{C}=\eta_{1} S^{*}\left(\mathrm{I} 1 \mid \mathrm{C}(s)=\mathrm{C}^{\prime}\right)+\eta_{2} S^{*}\left(\mathrm{I} 2 \mid \mathrm{C}(s)=\mathrm{C}^{\prime}\right)+\eta_{3} S^{*}\left(\mathrm{I} 3 \mid \mathrm{C}(s)=\mathrm{C}^{\prime}\right)+\left[1-\eta_{1}-\eta_{2}-\eta_{3}\right] S^{*}\left(\mathrm{I} 4 \mid \mathrm{C}(s)=\mathrm{C}^{\prime}\right),
$$

where the weights $\eta$ represent the shares of answers graded under each regime for all students with characteristic $\mathrm{C}(s)=\mathrm{C}^{\prime}$. The total treatment effect of a particular characteristic $\mathrm{C}^{\prime}$ being observable is the weighted average of the treatments when $C(g)=C^{\prime}$ and when $C(g) \neq C^{\prime}$. Thus:

$$
M_{C^{\prime}}=\left(\eta_{1}+\eta_{2}\right)\left[S^{*}\left(\mathrm{I} 1 \mid \mathrm{C}(g)=\mathrm{C}^{\prime}\right)-S^{*}\left(\mathrm{I} 2 \mid \mathrm{C}(g)=\mathrm{C}^{\prime}\right)\right]+\left(1-\eta_{1}-\eta_{2}\right)\left[S^{*}\left(\mathrm{I} 4 \mid \mathrm{C}(g)=\mathrm{C}^{\prime}\right)-S^{*}\left(\mathrm{I} 3 \mid \mathrm{C}(g)=\mathrm{C}^{\prime}\right)\right] .
$$

Equation (5) shows that the average treatment effect of a characteristic will depend on two factors: 1) The degree of endophilia and exophobia (the two bracketed expressions in (5)); and 2) The share of questions that are graded by graders with matching characteristics $\left(\eta_{1}+\eta_{2}\right)$ versus non-matching characteristics $\left(1-\eta_{1}-\eta_{2}\right)$.

We can also observe the behavior of individual graders toward the student groups as defined by $\mathrm{C}(s)$. Each grader scores answers written by many different students, some with characteristics that match hers, others with characteristics that do not match, some of whom are Blind, others Visible. Then for a grader $g$ we can calculate her average treatment of students, $\mathrm{T}^{\mathrm{g}}$, in a manner analogous to the average effect in (2) and obtain a distribution over all graders. More interesting for our purposes, we can estimate each grader's preferences for students who do and do not match their characteristics as:

$$
m_{M}{ }^{g}=S^{* g}(\mathrm{I} 1)-S^{* g}(\mathrm{I} 2) \text {; }
$$

and

$$
m_{N}{ }^{g}=S^{* g}(\mathrm{I} 4)-S^{* g}(\mathrm{I} 3)
$$

where $S^{* g}(\mathrm{I} j), j=1,2,3,4$, is the average over all students whose exams are scored by grader $g$ under each regime $\mathrm{I} j$. Using these grader-specific average treatments, we can then obtain the distributions of endophilia and exophobia as $\mathrm{f}\left(m_{M}\right)$ and $\mathrm{h}\left(m_{N}\right)$, providing specific analogues to the distributions discussed in Section II and presented in Figure 1. Thus, in addition to being able to distinguish the average extent of 
favoritism toward one's own group from the average extent of discrimination against other group(s), the data allow us to obtain complete distributions of agents' implicit preferences.

\section{Empirical Strategy and Basic Results}

To estimate the impacts of nationality and gender matches on the points that graders assigned to students' answers, and to infer the differences discussed above, we estimate the regression:

$$
\begin{aligned}
& S=\beta_{1} M A T C H^{*} V I S I B L E+\beta_{2} M A T C H^{*} B L I N D+\beta_{3} N O N-M A T C H^{*} V I S I B L E \\
& +\beta_{4} N O N-M A T C H^{*} B L I N D+\gamma^{\prime} X+\varepsilon,
\end{aligned}
$$

where here $S$ is a unit normal deviate calculated for each exam question, and the other variable names are self-explanatory. ${ }^{20}$ The matrix $X$ includes nationality or gender indicators for both students and graders, $\varepsilon$ is a zero-mean error term and the regression is estimated without a constant. From this equation the estimates of endophilia and exophobia are:

$$
M_{M}=S^{*}(\mathrm{I} 1)-S^{*}(\mathrm{I} 2)=\beta_{1}-\beta_{2}
$$

and:

$$
M_{N}=S^{*}(\mathrm{I} 4)-S^{*}(\mathrm{I} 3)=\beta_{4}-\beta_{3}
$$

Thus the estimates of (7) provide direct analogs to the concepts we seek to measure. Note that these calculations mean that endophilia (exophobia) is indicated by a positive $M_{M}\left(M_{N}\right)$.

One special benefit that we obtain from our setting is that we can be sure that the implied preferences on matching are driven by taste-based discrimination and not by other common confounding factors like unobserved heterogeneity. In our experimental setting we are comparing arguably identical groups whose only difference - because the treatment was random - is that the graders observed the names of some but not of other students. The experiment allows us explicitly to compare Visible to Blind German students. This means that anything specifically German, such as writing style in English or particular calligraphic patterns, washes out in this comparison. This framework also makes it easy to

\footnotetext{
${ }^{20}$ The distribution of the standardized question scores is roughly normal and slightly negatively skewed, but it is the same for all four groups defined by VISIBLE, BLIND, MATCH, and NON-MATCH.
} 
expand Equation (7) to include interactions with some of the graders' measurable characteristics and thus to examine how $M_{M}$ and $M_{N}$ vary with them. We deal with these extensions in Section VI.

The first two columns of Table 3 present the estimated $\beta$ and their standard errors for the basic equations describing matches/non-matches along the criteria of nationality and gender. Since the experimental design randomized by blocks of students within each course, we cluster the standard errors at the Intention-To-Treat and course (ITT-course) level, allowing for two clusters per course. We focus throughout on the estimates of $M_{M}$ and $M_{N}$ and their statistical significance.

It is clear that there is substantial endophilia by nationality in the grading. A student who matches the grader's nationality receives a score that is 0.17 standard deviations higher when her name is visible than when it is not. This addition to a matched student's grade is statistically significant at conventional levels. This effect is also economically important: Given that all the scores have been unit-normalized, it is equivalent to moving from the median score to the $57^{\text {th }}$ percentile of the distribution of scores. The size is similar to that of the effect of large differences in teacher quality on students' test scores that was found by Rivkin et al. (2005). While favoritism by nationality exists in grading, there is no apparent exophobia by nationality: The estimated impact of being visible when not matching by nationality is small and positive.

The results of estimating the regression examining gender matching are shown in Column (2) of Table 3. Although the point estimate suggests the existence of endophilia, we cannot reject the hypothesis that it is zero. ${ }^{21}$ For non-matches there is exophilia, but here too the impact is statistically insignificant and also minute. On average grading seems gender-neutral in all dimensions. ${ }^{22}$

\footnotetext{
${ }^{21}$ The small effects for gender could be a result of the graders being able to identify students' gender by the students' handwriting. We tested this by asking two raters (one of whom is an author but was not a grader) to guess the gender on the basis of the handwriting in a subsample of the actual exams. The gender guess was correct in 65 percent of the cases. This exceeds the 50-percent that could be obtained by throwing darts (although it equals what one would find using the student population average by gender). It may imply a small downward bias in these estimates.

${ }^{22}$ The results are also essentially the same when we include additional controls for seat number (see Figure 1) and the student's prior GPA.
} 
Going behind the information in Columns (1) and (2), we can ask whether, for examples, endophilia by nationality is the same for Dutch and German graders, and whether the absence of endophilia or exophobia exists for both male and female graders. We do this by expanding Equation (7) to include interactions of student nationality or gender with $M A T C H^{*} V I S I B L E, M A T C H^{*} B L I N D, N O N$ $M A T C H^{*} V I S I B L E$, and NON-MATCH*BLIND. Columns (3) of Table 3 show the estimates of this expanded specification by nationality. A comparison of the results suggests that endophilia by nationality arises more from the behavior of Dutch than of German graders, although the difference between the two point estimates is not statistically significant.

Columns (4) of Table 3 show estimates of expanding Equation (7) by gender. The results look very much like those in Column (2): Neither male nor female graders exhibit significant endophilia or exophobia, and for both men and women the absolute impacts are tiny. Again, there is no sign of either statistically significant or important differences in behavior depending on the match or non-match of the grader's and student's gender.

\section{Robustness and Extensions}

\section{A. Treatment Failures}

In interpreting these main results it is important to note that there are two potential sources of slippage in our treatment: Some students did not comply with the experimental instructions and wrote their name; and some graders may have looked up at least some of the students' names. ${ }^{23}$ To account for the first source of slippage we re-estimated the models described in the first two columns of Table 3 using intention to treat (ITT) as an instrument for VISIBLE. As Table 4 shows, the results are qualitatively identical to the ones in Table 3.

To account for the second source of slippage - that the grader may have been able to identify the characteristic of the Blind group — in the post-grading survey we asked graders whether they looked up

\footnotetext{
${ }^{23}$ Evidence on the magnitude of the first type of slippage can be seen in Table 2 in the differences between ITT and Treatment.
} 
any names on the exams that only contained ID numbers. Six of the thirty-three graders who responded to the survey acknowledged having done this. When we re-estimated (7) including only those graders who did not look up names, the estimated endophilia by nationality is the same, but even more significant statistically than for the entire sample. There is no significant exophobia/philia by gender among those graders who did not look up names. The results of both slippages suggest that, if anything, our results understate the true extent of favoritism by nationality.

\section{B. Distinguishing by Prior Grader-Student Contact and Exam Type}

The graders and exams differ along several dimensions on which we have information and which might affect their ability or interest in favoring/discriminating for or against students. We first look at whether the graders knew the students they graded, and thus whether endophilia/exophobia is present towards anonymous and familiar students alike. We have no specific hypothesis on this possibility. On the one hand, it could be that prejudices are overridden by personal experience with the students. If so, discriminatory preferences should be stronger toward unknown students. On the other hand, it might not be the characteristic per se that the graders pay attention to, but something that graders only get to observe on students they interact with and who match their characteristics. In this case discriminatory preferences should be stronger toward and against students whom the grader knows.

We construct an indicator of whether the grader may know a student based on whether the grader also taught him or her. Most of the teaching at the SBE is done in small groups of 10 to 15 students for about 10 sessions in each 7 -week block, so teachers have a fair chance to get to know their students. Some graders taught none of the students they graded, others taught all of the students they graded. By this measure the median grader knew 47 percent of the students graded (although obviously in most cases the grader could not identify individual students in the Blind group).

The first two columns of Table 5 present re-estimates of Equation (7), expanded to include interactions of the Know indicator with the four Match/Visible variables. The results show that endophilia by nationality is only present when graders did not know the students. This effect is twice as large as the mean effect in the baseline model. There is no evidence of exophobia by nationality regardless of whether 
the grader knew the student or not. There is some, marginally significant evidence of endophilia and exophilia by gender, but again only when the grader did not know the student.

The exams at the SBE differ in the extent to which they have mathematical questions. Answers on the more mathematical exams are arguably less ambiguous, so that favoritism/discrimination on them might be more difficult. To separate the more from the less mathematical exams we asked three raters (from the SBE's pool of potential graders) to rate the exams as mathematical or not. Two of the three agreed in their categorizations of all the exams, while the third agreed with the other two in 80 percent of the cases. We thus created an indicator for Mathematical when at least two of the three raters designated an exam as such, which occurred in 9 out of 25 exams.

The third and fourth columns of Table 5 present estimates of Equation (7), expanded to include interactions of the Mathematical indicator with the main variables. The point estimates suggest that endophilia by nationality is stronger for less mathematical exams. The point estimate for endophilia by gender is marginally significant for the more mathematical exams. This latter result is surprising, as one might expect that Blind exams might be less likely to be assignable to gender based on handwriting styles if the exam is more mathematical. None of the other results in the two columns is statistically significant.

\section{The Impact of Graders' Rational Expectations}

So far we have implicitly assumed that the graders are indifferent toward "blind" exams and treat these groups as a neutral baseline against which we measure endophilia and exophobia. When grading Blind exams, the grader might not be oblivious to the distribution of students' characteristics and might form rational expectations of the characteristics of the students who wrote those exams. As an extreme example, a grader who knows that all her students match her nationality will a fortiori know the nationality of any student in the Blind group.

Let $Z_{g}$ be the share of students in the course that match grader $g$ on the characteristic of interest, and let $\mathrm{e}$ and $\mathrm{x}$ be the grader's latent endophilic and exophobic preferences. Under rational expectations we can rewrite Equation (7) as:

(7') $S=\mathrm{e} \cdot M A T C H^{*} V I S I B L E+\mathrm{x} \cdot N O N-M A T C H^{*} V I S I B L E+\left[\mathrm{e} \cdot Z_{g}+\mathrm{x} \cdot\left(1-Z_{g}\right)\right]+\gamma_{2}{ }^{\prime} X+\varepsilon$, 
where, from the grader's perspective, the students can either visibly match him, visibly non-match him, or be in the Blind group. Equation (7') specifies that the grader will treat the students in the Blind group as the weighted average of how he would have treated students who matched him or not.

To determine whether assuming rational expectations about the Blind group's students can alter our results, we estimate ( $\left.7^{\prime}\right)$ by non-linear least squares. The results confirm our main findings: We again find endophilia by nationality, although of slightly lesser but still statistically significant magnitude-$0.117, \mathrm{p}=0.031$. We find no endophilia by gender and no exophobia by either gender or nationality. We can thus conclude that our main findings do not depend on whether graders are grading with rational expectations about their students' gender or nationality.

\section{Distinguishing by Graders' Other Characteristics}

We also examine whether discrimination or favoritism varies with grader experience and grader quality. We measure grader experience at this University as the number of separate courses taught or tutored during the grader's tenure. We have no hypotheses about how university-specific experience might mitigate or exacerbate endophilia/exophobia. On the one hand, the set of more experienced graders may exclude those whose behavior was so egregiously unfair that the University did not renew their contracts. On the other hand, more experienced graders may be secure in their positions and feel able to indulge their preferences for students who match their characteristics and/or against those who do not.

The total number of courses taught/tutored at the University since the online data became available (including the courses we are using here) ranges from 1 to 94 ; the $5^{\text {th }}, 50^{\text {th }}$ and $95^{\text {th }}$ percentiles, for which we present estimation results, are 1,8 and 59 courses. ${ }^{24}$ Figure 3 a presents the kernel density of courses taught by grader, which demonstrates the distribution's very long right tail. The first and second columns of Table 6 present re-estimates of Equation (7), expanded to include interactions of grader experience with the four match/visible variables.

\footnotetext{
${ }^{24} 59$ and 94 might seem outlandishly large; but at this University there are 6 teaching blocks in each academic year, so it is not difficult to accumulate 50 or more courses of experience.
} 
While the point estimate of the extent of endophilia by nationality is almost identical at the median value of grader experience to the estimate in Table 3, it is not quite significantly nonzero. Rather, the significant average endophilia shown in Table 3 results disproportionately from the behavior of the more experienced graders. By inference, they feel less inhibited about indulging their preferences for students who match their nationality. Inexperienced graders, perhaps because they feel themselves to be under greater scrutiny, show no significant endophilia (although the point estimate of their behavior is 60 percent of that of highly experienced graders). As with the basic estimates, there is no evidence of exophobia by nationality at any level of grader experience. The results by gender remain the same: Just as at the sample means, so too at various levels of grader experience the parameter estimates show no sign of any significant endophilia or exophobia.

We measure grader quality as the average of all the evaluations that the instructor received from students during her career at the University. Evaluations are given on a ten-point scale. In our sample the averages range from 6.5 to 9.2 , with the $5^{\text {th }}$ percentile being 7.1 , the median being 8.0 , and the $95^{\text {th }}$ percentile equaling 8.8. As Figure $3 \mathrm{~b}$ shows, while the distribution of average evaluations is not perfectly symmetric, it is not far from that.

We interact the grader's average instructional evaluation with all the variables in Equation (7) and present the results in Columns (3) and (4) of Table 6. Our finding of endophilia by nationality at the mean demonstrated in Table 3 arose from behavior that varies sharply with the regard in which graders have been held by students. Those graders/instructors who have been rated highest by students show no significant endophilia, and the point estimate of this effect is small. An instructor whose teaching has been rated at the median of this measure behaves much like the mean instructor-significantly and substantially favoring those who match her nationality, unsurprisingly given the symmetry in the distribution of teaching evaluations. The worst-rated instructors, however, favor those students who match their nationality much more strongly than does the median or average instructor. Implicitly a poorly rated instructor raises the score of the median student who matches her nationality from the mean to the $61^{\text {st }}$ percentile of the distribution of scores. There is no evidence of exophobia by nationality. As with all the 
other results, there is no evidence of endophilia or exophobia by gender, regardless of how badly or well the grader's teaching is rated by students. In sum, worse teachers behave differently from better ones, favoring students of their own nationality.

\section{The Average Treatment Effect of Visibility of a Student Characteristic}

To evaluate whether the visibility of names differentially favors or disadvantages certain groups of students, and also to see how these students would be affected by the introduction of anonymous grading, we calculate the average treatment effect (ATE) of each characteristic's visibility. Recall from Equation (5) that the ATE can be calculated as the difference between endophilia and exophobia, each weighted by the share of questions that was graded by graders with matching and non-matching characteristics. Table 6 shows the ATE of being seen as German, Dutch, or any other nationality, and of being seen as female or male. The point estimates for German and Dutch students are similar in size and (marginally) significantly positive, which shows that German and Dutch students both benefit from visible grading. The point estimates further suggest that other nationalities are disadvantaged by it, although the ATE is not statistically significant. Even if they are not suffering from an absolute disadvantage, however, the notion that other nationalities are disadvantaged becomes straightforward for situations in which they compete with German and Dutch students. An example is the allocation of student exchange positions at popular universities abroad, which is done based on relative grades. The difference between Germans and others is significant $(\mathrm{p}=0.004)$ as is the difference between Dutch and others $(\mathrm{p}=0.025)$. Consistent with our previous results, the point estimates for females and males are positive but smaller in size.

Columns (1) to (4) of Table 6 decompose the ATE by showing endophilia and exophobia (Columns (2) and (4)) and the share of students with the given characteristic that was graded under each regime (Columns (1) and (3)). (The estimated effects of endophilia and exophobia are taken from Table 3.) The ATE for German and Dutch students is small because of the relatively small shares of questions that are graded by graders of the same nationality. This outcome results from the heterogeneous mix of nationalities of the graders. It is easy to simulate the sizes of these effects for a situation in which a large share of the students in either category were matched to the graders. Notice also that the mix of graders is 
not always the most important determinant of the ATE: The difference between the effects when matched and not matched for females is rather small, so that the ATE will be small regardless of the gender mix of graders.

\section{Heterogeneity in the Distribution of Preferences}

The results thus far describe either average responses over all graders of endophilia or exophobia by nationality or gender, or examine how this behavior differs in relation to a few of the graders' specific characteristics. In this section we first consider the shapes of the entire distributions of graders' preferences and then calculate their correlation.

To obtain a feel for why examining heterogeneity in preferences might be interesting, consider the kernel density estimates of endophilia and exophobia by nationality, shown in Figure 4, and their kernel densities by gender, shown in Figure 5. Each kernel is based on those graders for whom we could infer the extent of both endophilia and exophobia (for nationality, 24 graders, for gender, 38 graders). ${ }^{25}$ The estimates along the criterion of nationality suggest that preferences are distributed fairly symmetrically, in the case of endophilia around a positive mean, and around zero in the case of exophobia. Both densities are consistent with our inferences in Table 3 about the mean effects. The same conclusion is suggested by the kernel of exophobia by gender. The kernel of endophilia by gender is completely different. While the estimates suggest endophilia by the median grader, a few graders are apparently highly endophobic. This asymmetry may have generated the estimated absence of endophilia by gender on average that we showed in Table 3, but that inference at the means hides a substantial skewness in preferences. ${ }^{26}$

\footnotetext{
${ }^{25}$ We derive the shape of the graders' preferences based on the estimates of $m_{M}{ }^{g}$ and $m_{N}{ }^{g}$. We infer these two measures for each grader based on how each scores the student who does or does not match them under the blind and visible regimes.

${ }^{26} \mathrm{We}$ can examine whether extreme values in the distributions of preferences for nationality or gender are driving our mean effects. We trim those graders with the most extreme preferences from the samples, dropping the two most extremely endophilic/endophobic and exophobic/exophilic graders in each case. Despite the asymmetry of the distribution of $m_{M}$ in Figure 5, even there trimming does not qualitatively alter the conclusions about the absence of endophilia or exophobia by gender on average. In the other three cases too the conclusions are not greatly modified by this trimming exercise.
} 
By observing the entire distribution of preferences we can also test two hypotheses: 1) There is evidence of endophilia or exophobia in the overall distribution (not just at the mean), and 2) There is heterogeneity in endophilia or exophobia among graders. Testing these two hypotheses is equivalent to testing whether $m_{M}{ }^{g}=0\left(m_{N}{ }^{g}=0\right)$ for all $g$, and whether the $m_{M}{ }^{g}\left(m_{N}{ }^{g}\right)$ are equal to each other for all $g$, respectively. The F-tests of these hypotheses (eight in total) all reject the null hypothesis at all conventional significance levels, showing that endophilia and exophobia in both nationality and gender are real phenomena (even though at the mean only endophilia by nationality seems to matter), and that there is significant heterogeneity in these preferences across graders.

As we showed in Section II, the impact of the interaction of endophilia and exophobia depends on their correlation across potentially discriminating agents. In our data the correlations are -0.36 for preferences on nationality, and -0.16 for preferences on gender: Those who are more endophilic are less exophobic. Interestingly, and remarkably, in the GSS data summarized in Table 1, the correlations are in the same direction: Those Whites who feel closer to Whites also feel closer to Blacks, and to roughly the same extent as implied by behavior in our sample.

\section{Conclusions and Implications}

We have demonstrated that what is called discrimination-a relative difference in outcomes between two groups - is composed of differential treatment of the in-group and the out-group, and that it is possible in real-world situations to measure the sizes of these two components simultaneously. In our example we find that most of the apparent discrimination by nationality results from substantial endophilia and that there is no evidence on average of exophobia. We find no evidence of differential treatment by gender on average, whether or not the discriminating agents match their subjects.

These are average effects. At least as interesting is the heterogeneity in the demonstrated preferences of the individuals deciding how to treat those who match or do not match them. We have shown that apparently discriminatory outcomes can be vitiated in a variety of ways, operating both on the endophilic and exophobic preferences of the discriminating agents and their characteristics. Not surprisingly, a neutral outcome can also be achieved in a variety of ways. 
We also show the importance of measuring both endophilia and endophobia simultaneously in the labor market: Their joint distribution will influence market-based measures of discrimination. This result makes it even clearer that they are non-redundant measures. It also forces us to reconsider what we know about the effectiveness of anti-discriminatory policies and the advances against discrimination in the labor market. The change over time in measures of discrimination, such as the market discrimination coefficient, may not only reflect a change in the expressed preferences of the marginal individual. It may also reflect a change in the correlation between endophilia and exophobia. This changing correlation might explain the unchanging racial wage gap over a period when racial attitudes appear to have become more tolerant.

Having shown that we can distinguish endophilia from exophobia, it is also worth considering how policy might be tailored to reduce relative differences arising from prejudice. Assume that our results carry over to the labor and other markets, and that endophilia is the main source of apparently discriminatory outcomes. If so, we can infer, for example, that moral suasion that stresses to members of the majority group that minority-group members are not "bad" might be ineffective.

Can the distinctions that we have defined and measured here be inferred in the still more important labor-market context? One might imagine cases where a majority group deals with several minority groups, about one of which it feels demonstrably neutral. In that case too endophilia and exophobia (toward the other minorities) are identifiable. So too, one might link differences in economic outcomes to information on attitudes in a population about one's own and other groups. The main point is that these preferences generate different outcomes with different distributions of welfare, so that determining their relative size is economically important and, as we have shown, possible. 


\section{References}

Ali M. Ahmed, "Group Identity, Social Distance and Intergroup Bias," Journal of Economic Psychology, 28 (2007): 324-37.

Gordon Allport, The Nature of Prejudice. Cambridge, MA: Addison-Wesley, 1954.

Joseph Altonji and Rebecca Blank, "Race and Gender in the Labor Market," in Orley Ashenfelter and David Card, eds., Handbook of Labor Economics, Vol 3C. Amsterdam: North-Holland, 1999, pp. 3143-3259.

Jason Abrevaya and Daniel Hamermesh, "Charity and Favoritism in the Field: Are Female Economists Nicer (to Each Other)?" Review of Economics and Statistics, 94 (Feb. 2012): 202-7.

Manuel Baguës and Berta Esteve-Volart, "Can Gender Parity Break the Glass Ceiling? Evidence from a Repeated Randomized Experiment," Review of Economic Studies, 77 (Oct. 2010): 1301-28.

Gary Becker, The Economics of Discrimination. Chicago: University of Chicago Press, 1957.

Rebecca Blank, "The Effects of Double-Blind versus Single-Blind Refereeing: Experimental Evidence from the American Economic Review," American Economic Review, 81 (Dec. 1991): 1041-67.

Glen Cain, "The Economic Analysis of Labor Market Discrimination: A Survey," in Orley Ashenfelter and Richard Layard, eds., Handbook of Labor Economics, Vol. 2. Amsterdam: North-Holland, 1986, pp. 693-785.

Ana Rute Cardoso and Rudolf Winter-Ebmer, "Female-Led Firms and Gender Wage Policies," Industrial and Labor Relations Review, 64 (Oct. 2010): 143-63.

Kerwin Charles and Jonathan Guryan, "Prejudice and Wages: An Empirical Assessment of Becker's The Economics of Discrimination," Journal of Political Economy, 116 (Oct. 2008): 773-809.

Thomas Dee, “A Teacher Like Me: Does Race, Ethnicity or Gender Matter?" American Economic Association, Papers and Proceedings, 95 (May 2005): 158-65.

Alan Dillingham, Marianne Ferber and Daniel Hamermesh, "Gender Discrimination by Gender: Voting in a Professional Society," Industrial and Labor Relations Review, 47 (July 1994): 622-33.

Stephen Donald and Daniel Hamermesh, "What Is Discrimination? Gender in the American Economic Association, 1935-2004," American Economic Review, 96 (Sept. 2006): 1283-92.

Jan Feld and Nicolás Salamanca, "Grading Expectations," Unpublished paper, SBE, Maastricht University, 2013.

Chaim Fershtman, Uri Gneezy and Frank Verboven, "Discrimination and Nepotism: The Efficiency of the Anonymity Rule," Journal of Legal Studies, 34 (June 2005): 371-96.

Roland Fryer, "Racial Inequality in the $21^{\text {st }}$ Century: The Declining Significance of Discrimination," in Orley Ashenfelter and David Card, eds., Handbook of Labor Economics, Vol. 4B. Amsterdam: Elsevier, pp. 855-971. 
Laura Giuliano, David Levine and Jonathan Leonard, "Racial Bias in the Manager-Employee Relationship: An Analysis of Quits, Dismissals and Promotions at a Large Retail Firm," Journal of Human Resources, 46 (Winter 2011): 26-52.

Matthew Goldberg, "Discrimination, Nepotism and Long-Run Wage Differentials," Quarterly Journal of Economics, 97 (May 1982): 307-19.

Claudia Goldin and Cecilia Rouse, "Orchestrating Impartiality: The Impact of "Blind" Auditions on Female Musicians," American Economic Review, 90 (Sept. 2000): 715-41.

Björn Tyrefors Hinnerich, Erik Höglin and Magnus Johannesson, "Are Boys Discriminated in Swedish High Schools?” Economics of Education Review, 30 (Aug. 2011): 682-90.

Victor Lavy, “Do Gender Stereotypes Reduce Girls' or Boys’ Human Capital Outcomes? Evidence from a Natural Experiment" Journal of Public Economics, 92 (Oct. 2008): 2083-105.

Steven Levitt and John List, "What Do Laboratory Experiments Measuring Social Preferences Reveal About the Real World?" Journal of Economic Perspectives, 21 (Spring 2007): 153-74.

Christopher Parsons, Johan Sulaeman, Michael Yates and Daniel Hamermesh, "Strike Three: Discrimination, Incentives and Evaluation," American Economic Review, 101 (June 2011): 141035 .

Joseph Price and Justin Wolfers, "Racial Discrimination among NBA Referees," Quarterly Journal of Economics, 125 (Nov. 2010): 1859-87.

Steven Rivkin, Eric Hanushek and John Kain, "Teachers, Schools and Academic Achievement," Econometrica, 73 (March 2005): 417-58. 
Table 1. Endophilia and Exophobia in the U.S. General Social Survey, 1996-2006, 9-point scale*

\section{Time period:}

1996-2000

2004-2006

\section{WHITES}

Feel Close to Whites

$\begin{array}{cc}7.06 & 6.966 \\ (0.031) & (0.038)\end{array}$

Feel Close to Blacks

5.121

5.494

$(0.032)$

$(0.039)$

$\mathrm{N}$

3,550

2,174

$\underline{\rho}$

0.146

0.226

\section{BLACKS}

Feel Close to Whites

5.799

5.945

(0.084)

(0.106)

Feel Close to Blacks

$\begin{array}{rr}7.547 & 7.685 \\ (0.079) & (0.093)\end{array}$

$\mathrm{N}$

651

387

$\rho$

0.242

0.318

*In general, how close do you feel to ...? 9 = very close; $1=$ not close at all. Standard errors of means in parentheses. 
Table 2. Student Characteristics by Intended and Actual Treatment Status*

\begin{tabular}{|c|c|c|c|c|c|c|c|c|}
\hline \multicolumn{9}{|c|}{ Internal validity: Pre-experiment } \\
\hline & & \multirow{2}{*}{\multicolumn{3}{|c|}{$\begin{array}{r}(1) \\
\text { Blind }\end{array}$}} & \multicolumn{3}{|c|}{ (2) } & \multirow{3}{*}{$\begin{array}{l}\text { p-value of difference } \\
\text { Blind-Visible }\end{array}$} \\
\hline & & & & & & Visible & & \\
\hline & & Mean & $\mathrm{SD}$ & $\mathrm{N}$ & Mean & $\mathrm{SD}$ & $\mathrm{N}$. & \\
\hline \multirow[t]{2}{*}{ Female } & ITT & 0.369 & 0.483 & 452 & 0.352 & 0.478 & 1,043 & {$[0.502]$} \\
\hline & Treatment & 0.363 & 0.482 & 399 & 0.355 & 0.479 & 1,096 & {$[0.758]$} \\
\hline \multirow[t]{2}{*}{ German } & ITT & 0.374 & 0.484 & 452 & 0.353 & 0.478 & 1,043 & {$[0.420]$} \\
\hline & Treatment & 0.373 & 0.484 & 399 & 0.354 & 0.478 & 1,096 & {$[0.486]$} \\
\hline \multirow[t]{2}{*}{ Dutch } & ITT & 0.363 & 0.481 & 452 & 0.343 & 0.475 & 1,043 & {$[0.452]$} \\
\hline & Treatment & 0.351 & 0.478 & 399 & 0.349 & 0.477 & 1,096 & {$[0.932]$} \\
\hline \multirow[t]{2}{*}{ GPA } & ITT & 7.197 & 0.628 & 443 & 7.215 & 0.665 & 1,021 & {$[0.607]$} \\
\hline & Treatment & 7.178 & 0.618 & 389 & 7.221 & 0.667 & 1,075 & {$[0.241]$} \\
\hline \multirow[t]{2}{*}{ Participation } & ITT & 7.690 & 0.986 & 306 & 7.633 & 1.031 & 706 & {$[0.386]$} \\
\hline & Treatment & 7.612 & 0.968 & 263 & 7.664 & 1.035 & 749 & {$[0.452]$} \\
\hline \multirow[t]{2}{*}{ Presentation } & ITT & 7.795 & 1.164 & 191 & 7.930 & 1.059 & 436 & {$[0.179]$} \\
\hline & Treatment & 7.758 & 1.172 & 181 & 7.942 & 1.055 & 446 & {$[0.070]$} \\
\hline \multirow[t]{2}{*}{ Term paper } & ITT & 7.870 & 0.665 & 109 & 7.743 & 0.898 & 281 & {$[0.126]$} \\
\hline & Treatment & 7.870 & 0.697 & 97 & 7.748 & 0.882 & 293 & {$[0.166]$} \\
\hline
\end{tabular}

Internal validity: Within-experiment

(1)

Blind

\begin{tabular}{llllcc} 
& & & \multicolumn{3}{c}{ Blind } \\
\cline { 1 - 3 } \cline { 5 - 6 } \cline { 5 - 6 } Multiple Choice exams & ITT & & 5.829 & 1.972 & 277 \\
& Treatment & & 5.792 & 2.009 & 253 \\
\hline Fill-In-The-Blank exams & ITT & & 5.325 & 2.208 & 152 \\
& Treatment & & 5.367 & 2.167 & 148
\end{tabular}

(2)

Visible

\begin{tabular}{ccc}
\multicolumn{3}{c}{ Visible } \\
\hline Mean & SD & $\mathrm{N}$ \\
\hline 6.043 & 1.942 & 661 \\
6.049 & 1.928 & 685 \\
\hline 5.555 & 1.996 & 382 \\
5.536 & 2.016 & 386
\end{tabular}

p-value of difference Blind-Visible

[0.128]

[0.078]

[0.264]

[0.411]

*p-values of differences between the Visible and Blind groups are calculated with standard errors clustered by student. 
Table 3. Basic Estimates of the Extent of Favoritism and Discrimination by Nationality and Gender $(\mathrm{N}=\text { 9330 })^{*}$

\begin{tabular}{|c|c|c|c|c|c|c|c|}
\hline \multirow[b]{2}{*}{ Interaction with: } & \multirow{2}{*}{$\begin{array}{c}(1) \\
\text { Nationality } \\
- \\
\end{array}$} & \multirow{2}{*}{$\begin{array}{c}(2) \\
\text { Gender } \\
- \\
\end{array}$} & \multicolumn{3}{|c|}{$\begin{array}{c}\text { (3) } \\
\text { Nationality }\end{array}$} & \multicolumn{2}{|c|}{$\begin{array}{c}(4) \\
\text { Gender }\end{array}$} \\
\hline & & & German & Dutch & Other & Female & Male \\
\hline \multirow[t]{2}{*}{ (1) $M A T C H * V I S I B L E$} & 0.287 & 0.203 & 0.306 & -0.012 & - & 0.156 & -0.039 \\
\hline & $(0.038)$ & $(0.041)$ & $(0.021)$ & $(0.099)$ & - & $(0.028)$ & $(0.027)$ \\
\hline \multirow[t]{2}{*}{ (2) $M A T C H^{*} B L I N D$} & 0.115 & 0.146 & 0.165 & -0.204 & - & 0.101 & -0.101 \\
\hline & $(0.081)$ & $(0.069)$ & $(0.101)$ & $(0.106)$ & - & $(0.075)$ & $(0.042)$ \\
\hline \multirow[t]{2}{*}{ (3) NON-MATCH*VISIBLE } & 0.177 & 0.206 & 0.148 & -0.048 & -0.123 & 0.150 & -0.101 \\
\hline & $(0.050)$ & $(0.062)$ & $(0.070)$ & $(0.053)$ & $(0.067)$ & $(0.047)$ & $(0.046)$ \\
\hline \multirow[t]{2}{*}{ (4) $N O N-M A T C H^{*} B L I N D$} & 0.172 & 0.174 & 0.060 & -0.095 & -0.035 & 0.053 & -0.071 \\
\hline & $(0.057)$ & $(0.055)$ & $(0.080)$ & $(0.077)$ & $(0.072)$ & $(0.038)$ & $(0.079)$ \\
\hline Endophilia [(1)-(2)] & 0.172 & 0.058 & 0.140 & 0.193 & - & 0.055 & 0.062 \\
\hline$p=$ & {$[0.028]$} & {$[0.260]$} & {$[0.171]$} & {$[0.049]$} & - & {$[0.471]$} & {$[0.188]$} \\
\hline Exophobia [(3)-(4)] & -0.005 & -0.033 & -0.087 & -0.047 & 0.088 & -0.097 & 0.030 \\
\hline $\mathrm{p}=$ & {$[0.904]$} & [0.619] & {$[0.098]$} & {$[0.531]$} & {$[0.180]$} & {$[0.124]$} & {$[0.740]$} \\
\hline
\end{tabular}

Adj. $R^{2}$

$0.015 \quad 0.014$

0.017

0.010

*Standard errors in parentheses and p-values in square brackets. Both are clustered by ITT-Course. Columns (1) and (2) present the estimates of Equation (7) without a constant. (3) and (4) are based on Equation (7), with the main variables interacted with CHARACTERISTIC, where CHARACTERISTIC are indicators for nationality in (3) and for gender in (4). $\mathrm{MATCH}^{*}$ Other interactions in (3) are empty because we define $\mathrm{MATCH}=1$ only for German and Dutch students. Other nationalities almost never matched. 
Table 4. The Effects of Treatment Slippage by Students and Graders on Estimates of Endophilia and Exophobia*

\begin{tabular}{|c|c|c|c|c|}
\hline \multirow[b]{2}{*}{ Regression: } & $\begin{array}{c}(1) \\
\text { Nationality }\end{array}$ & $\begin{array}{c}(2) \\
\text { Gender }\end{array}$ & $\begin{array}{c}\text { (3) } \\
\text { Nationality }\end{array}$ & $\begin{array}{c}(4) \\
\text { Gender }\end{array}$ \\
\hline & \multicolumn{2}{|c|}{ IV } & \multicolumn{2}{|c|}{ No Look-up names only } \\
\hline Endophilia & 0.193 & 0.092 & 0.174 & 0.002 \\
\hline$p=$ & {$[0.034]$} & {$[0.222]$} & {$[0.009]$} & {$[0.971]$} \\
\hline Exophobia & -0.033 & -0.055 & -0.008 & -0.103 \\
\hline $\mathrm{p}=$ & {$[0.538]$} & {$[0.457]$} & {$[0.878]$} & {$[0.093]$} \\
\hline $\mathrm{N}$ & 9,330 & 9,330 & 5,108 & 5,108 \\
\hline Adj. $R^{2}$ & 0.015 & 0.013 & 0.015 & 0.015 \\
\hline
\end{tabular}


Table 5. Endophilia and Exophobia When Graders Know the Students They Grade, and When the Exams are Mathematical $(\mathrm{N}=9330 *$

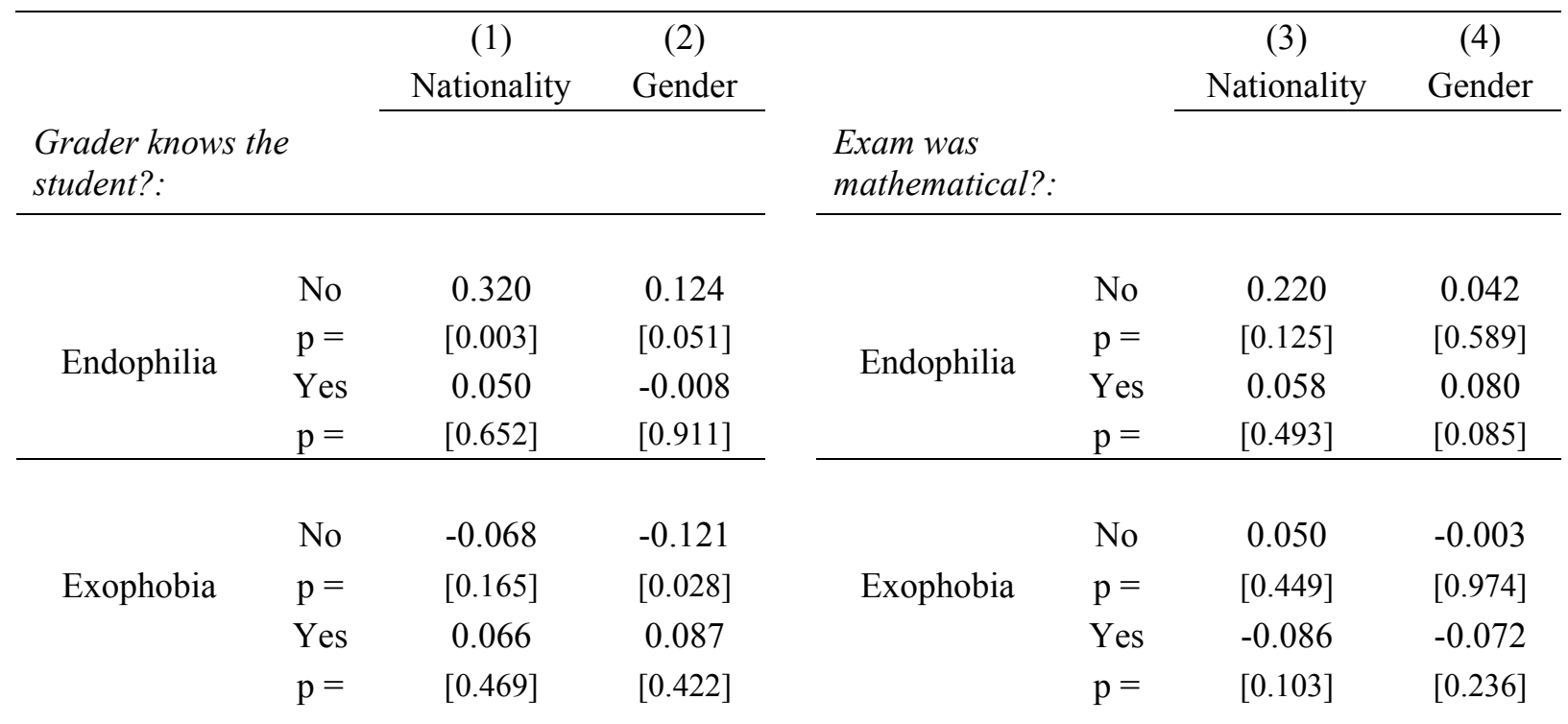

*p-values in squared brackets, clustered at the ITT-Course level. We report linear combinations based on extensions of Equation (7). Columns (1) and (2) report interactions of the main variables with GRADERKNOWSSTUDENT, Columns (3) and (4) of the main variables with MATHEMATICALEXAM. 
Table 6. Effects of Grader Experience and Grader Teaching Quality on Outcomes ( $=9197)^{*}$

\begin{tabular}{|c|c|c|c|c|c|}
\hline \multirow[b]{2}{*}{ At the $\mathrm{m}^{\text {th }}$ percentile of: } & \multirow[t]{2}{*}{ Percentile: } & $\begin{array}{c}(1) \\
\text { Nationality }\end{array}$ & $\begin{array}{c}(2) \\
\text { Gender }\end{array}$ & $\begin{array}{c}(3) \\
\text { Nationality }\end{array}$ & $\begin{array}{c}(4) \\
\text { Gender }\end{array}$ \\
\hline & & \multicolumn{2}{|c|}{ Experience } & \multicolumn{2}{|c|}{ Teacher Quality } \\
\hline \multirow{6}{*}{ Endophilia } & 5 th & 0.154 & 0.077 & 0.378 & 0.020 \\
\hline & $\mathrm{p}=$ & {$[0.162]$} & {$[0.202]$} & {$[0.057]$} & {$[0.853]$} \\
\hline & 50 th & 0.166 & 0.074 & 0.168 & 0.072 \\
\hline & $\mathrm{p}=$ & {$[0.097]$} & {$[0.171]$} & {$[0.137]$} & {$[0.140]$} \\
\hline & 95 th & 0.248 & 0.048 & 0.056 & 0.100 \\
\hline & $\mathrm{p}=$ & {$[0.001]$} & {$[0.505]$} & {$[0.747]$} & {$[0.138]$} \\
\hline \multirow{6}{*}{ Exophobia } & 5 th & -0.024 & 0.005 & -0.018 & -0.253 \\
\hline & $\mathrm{p}=$ & {$[0.639]$} & {$[0.945]$} & {$[0.863]$} & [0.059] \\
\hline & 50 th & -0.016 & -0.009 & -0.005 & -0.013 \\
\hline & $\mathrm{p}=$ & {$[0.718]$} & {$[0.893]$} & {$[0.900]$} & {$[0.838]$} \\
\hline & 95 th & 0.045 & -0.117 & 0.001 & 0.114 \\
\hline & $\mathrm{p}=$ & {$[0.635]$} & {$[0.107]$} & {$[0.982]$} & {$[0.249]$} \\
\hline $\begin{array}{l}\text { Main effects: } \\
\text { p-value of interactions: }\end{array}$ & & $\begin{array}{c}\text { Yes } \\
{[0.860]}\end{array}$ & $\begin{array}{c}\text { Yes } \\
{[0.001]}\end{array}$ & $\begin{array}{c}\text { Yes } \\
{[0.599]}\end{array}$ & $\begin{array}{c}\text { Yes } \\
{[0.150]}\end{array}$ \\
\hline Adj. $R^{2}$ & & 0.015 & 0.004 & 0.002 & 0.001 \\
\hline
\end{tabular}


Table 7. The Average Treatment Effect (ATE) of the Visibility of Student Characteristics*

\begin{tabular}{|c|c|c|c|c|c|c|}
\hline & Total ATE & p-value & $\begin{array}{c}(1) \\
\text { Share } \\
\text { matched } \\
(\eta 1+\eta 2)\end{array}$ & $\begin{array}{c}\text { (1) } \\
\text { Endophilia }\end{array}$ & $\begin{array}{c}(1) \\
\text { Share not } \\
\text { matched } \\
(1-\eta 1-\eta 2)\end{array}$ & $\begin{array}{c}(1) \\
\text { Exophobia }\end{array}$ \\
\hline German & 0.103 & {$[0.050]$} & 0.29 & 0.140 & 0.71 & -0.087 \\
\hline Dutch & 0.107 & {$[0.068]$} & 0.41 & 0.193 & 0.59 & -0.047 \\
\hline Other & 0.088 & {$[0.180]$} & - & - & 1 & 0.088 \\
\hline Female & 0.078 & {$[0.142]$} & 0.45 & 0.055 & 0.55 & -0.097 \\
\hline Male & 0.027 & {$[0.548]$} & 0.62 & 0.062 & 0.38 & 0.030 \\
\hline
\end{tabular}

*p-values in square brackets, clustered at the ITT-Course level. The ATE is calculated as in Equation (5). Columns (1) and (3) show the share of questions for a given characteristic which were graded by graders with matching and non-matching characteristics. Columns (2) and (4) show the ATE on the treated, as reported in Table 3. 


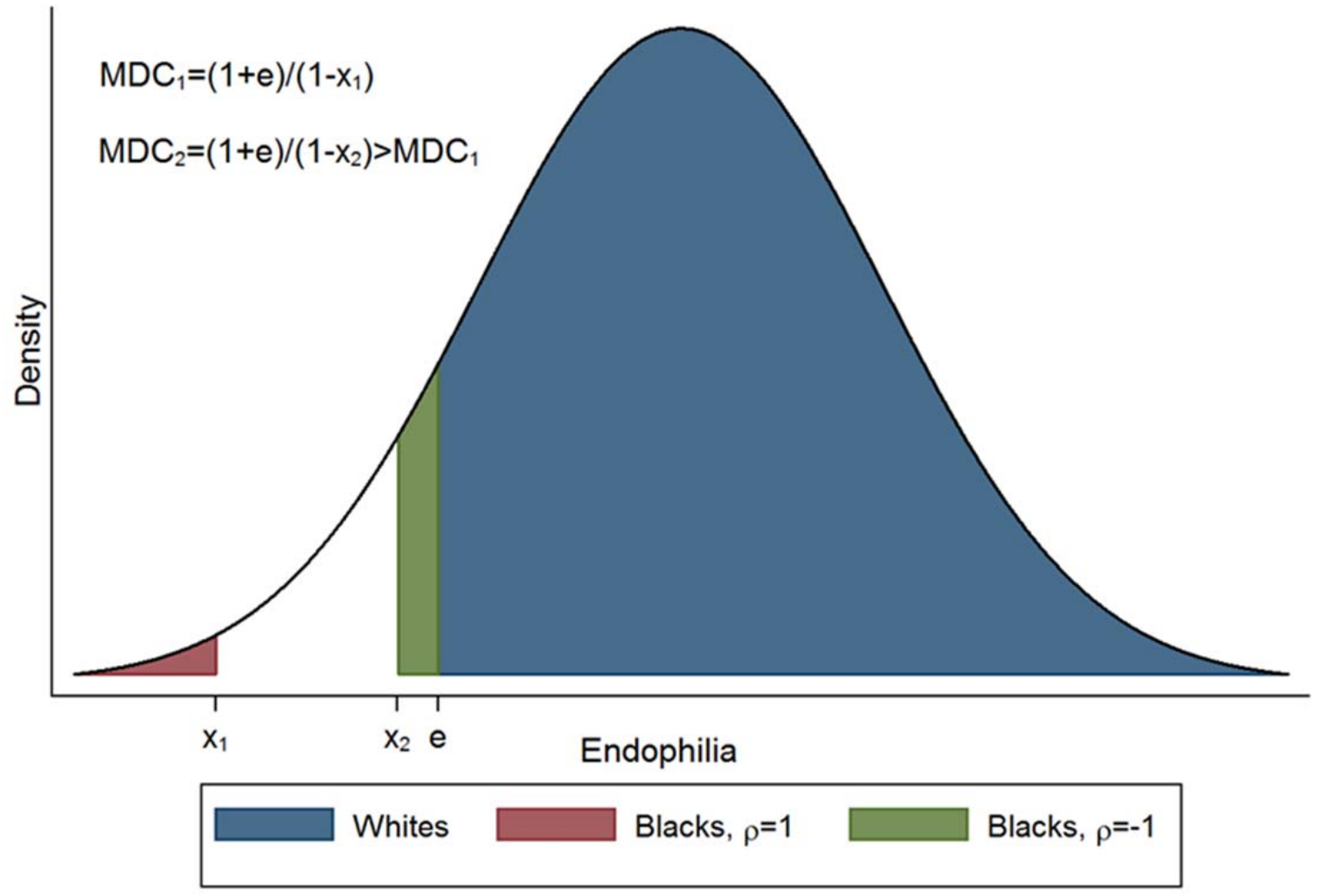

Exophobia

Case $1\left(\mathrm{x}_{1}\right)$ :

Exophobia

Case $2\left(x_{2}\right)$ :

Figure 1. Black and White Wages in Polar Cases of Endophilia and Exophobia*

*In constructing this graph we assume that some positions remain vacant after all employees are allocated. Unallocated jobs are shown in the white area below the curve. This assumption, however, is only for illustrative purposes; it is not needed for the model's results in any way. 


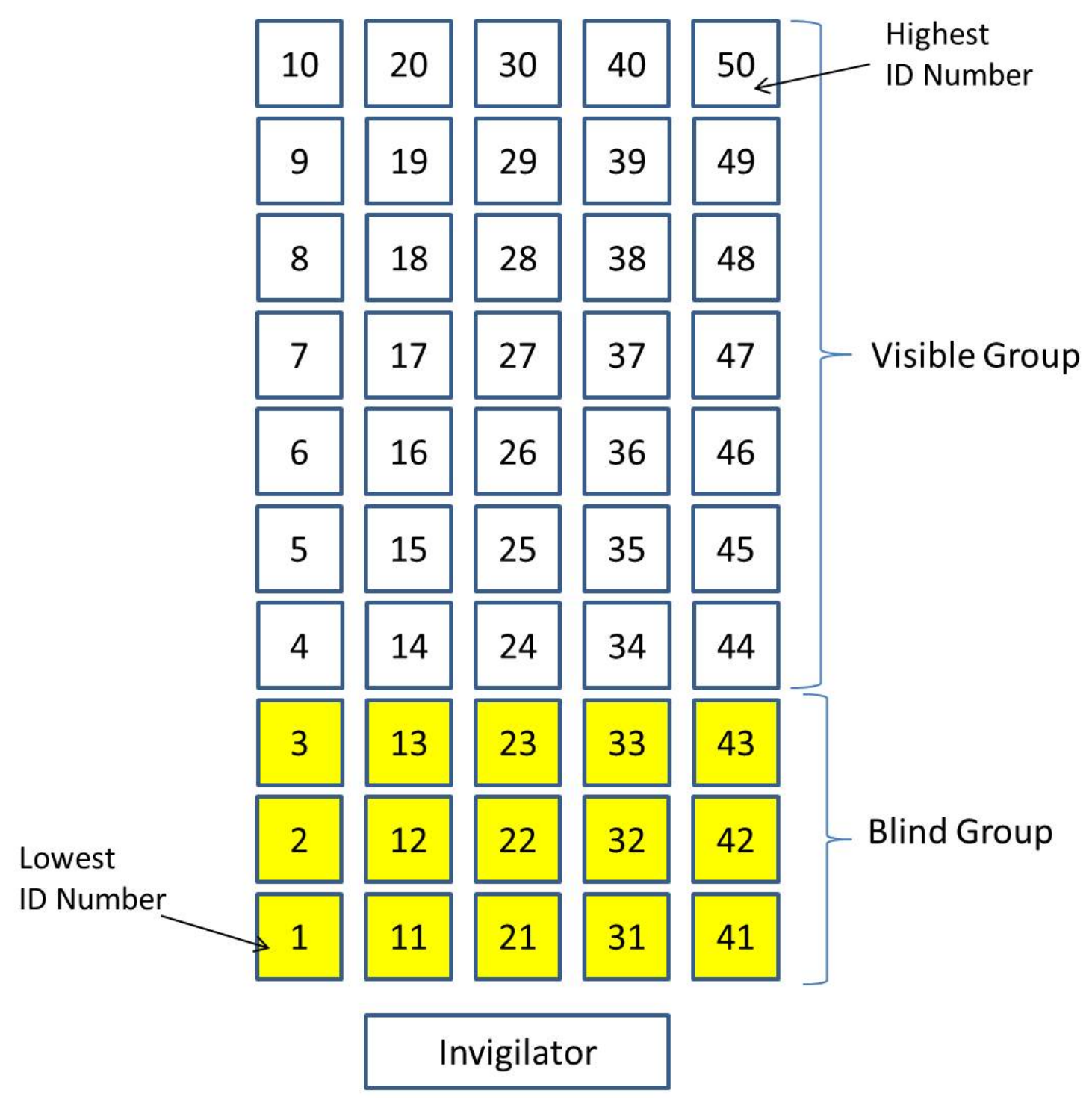

Figure 2: Seating Arrangement for the Experiment*

* One square represents one desk. Students were seated in order of their ID numbers. Each number indicates the order of student ID numbers in each block. The student with the lowest ID number sat in desk 1, the one with the highest ID in desk 50. Rows 1-3 had yellow sheets on the desks with instructions not to write their name, thus creating the Blind group. Rows 4-10 had no extra sheets. In these rows students were expected to write their name to create the Visible group. 


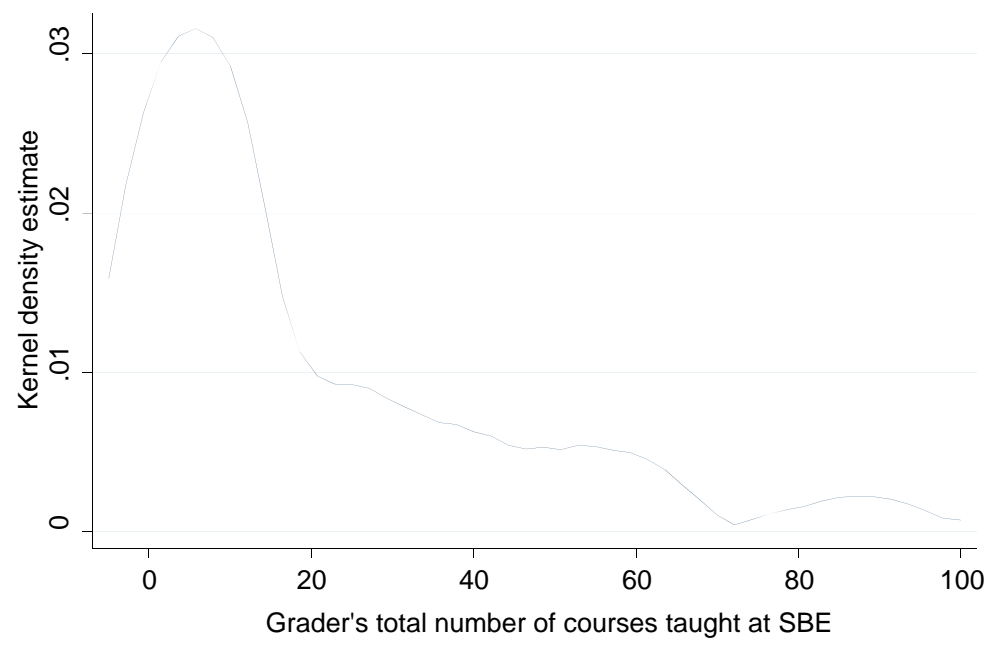

Figure 3a. Kernel Density of the Distribution of Grader Experience

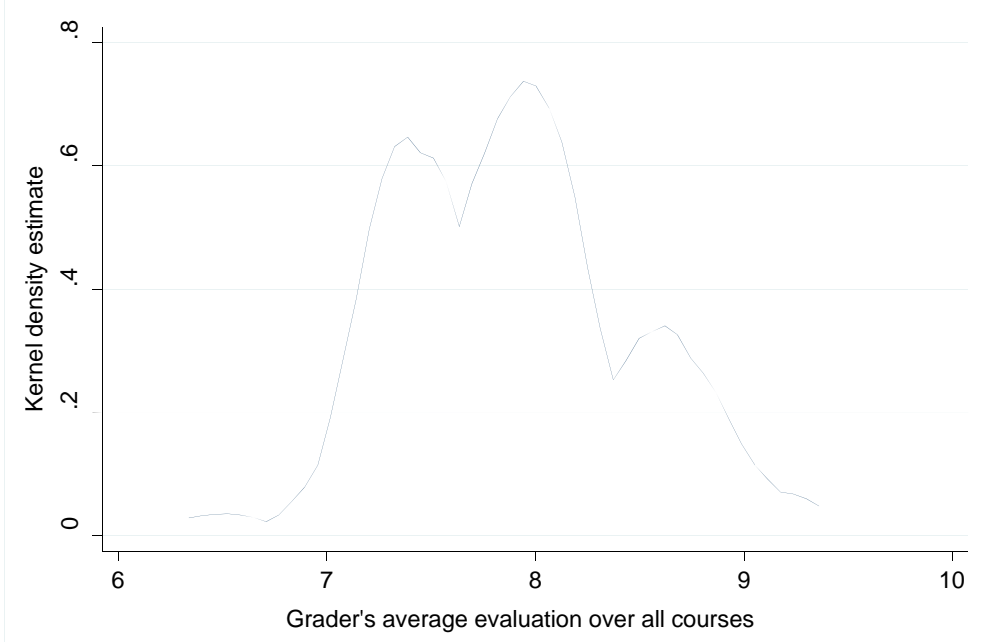

Figure 3b. Kernel Density of the Distribution of Student Evaluations of Graders 


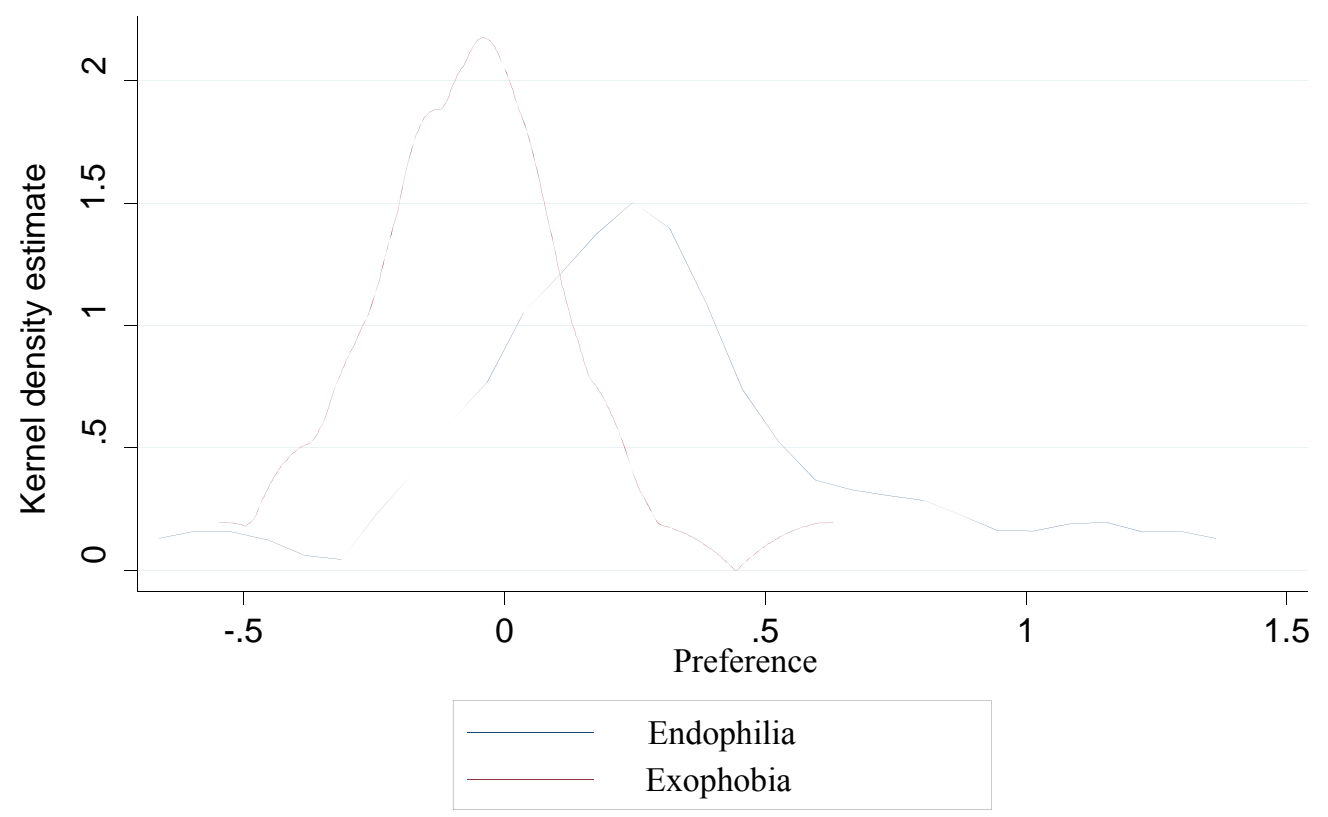

Figure 4. Kernel Density Estimates of Graders' Preferences by Nationality 


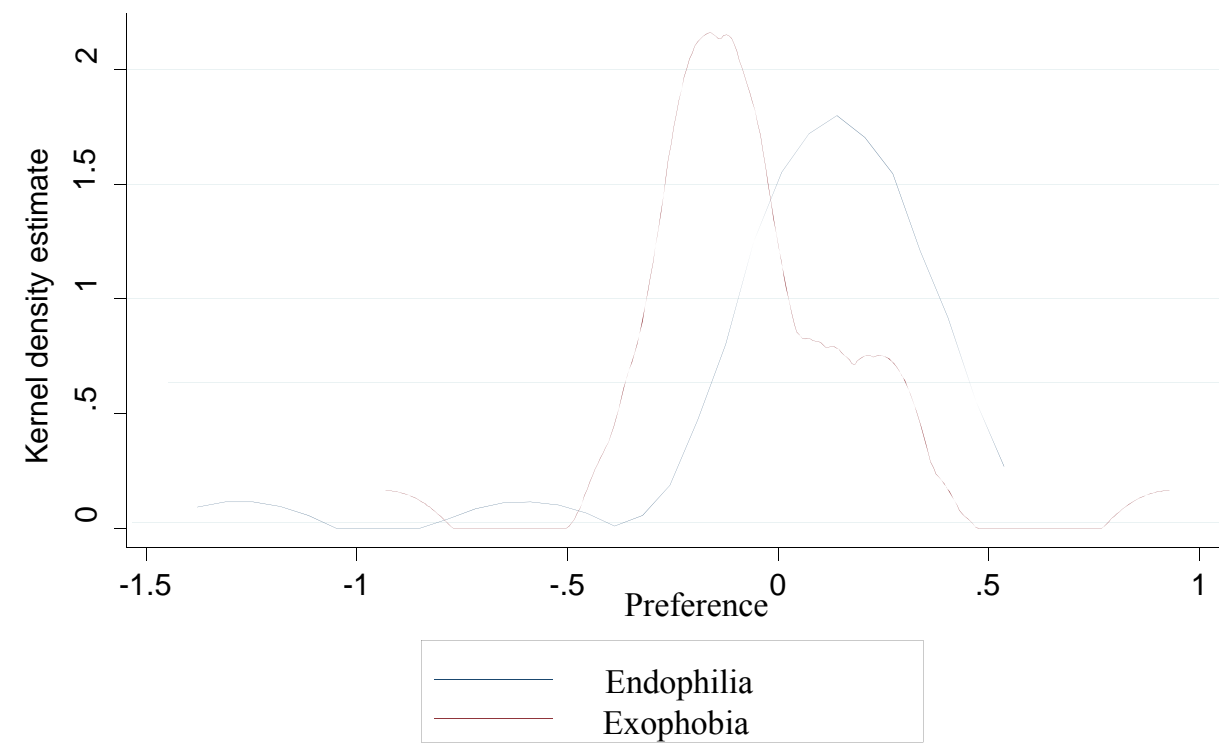

Figure 5. Kernel Density Estimates of Graders' Preferences by Gender 